\title{
The Evaluation of Mobile Sector in Turkey in Terms of Mobile Supply Chain Management Practices
}

\author{
Zumrut Ecevit Sati ${ }^{1}$ and Burak Oclu ${ }^{2}$ \\ ${ }^{1}$ Istanbul University, Faculty of Political Sciences \\ zsati@istanbul.edu.tr \\ ${ }^{2}$ Istanbul University, Institute of Social Sciences \\ burak.oclu@gmail.com
}

\begin{abstract}
Today companies face enormous pressure to reduce costs while increasing innovation and improving customer service and responsiveness. Supply Chain Management enables collaboration, planning, execution and coordination of the entire supply network, empowering companies to adapt their supply chain processes to an ever-changing competitive environment. Obviously, companies should replace traditional linear supply chains with adaptive supply chain networks in which partners are given simultaneous, accurate information about purchase, production, demand, supply, sale and other operational activities. In order to compete in the market place, mobile supply chains remedy their products and services in order to meet the needs of the increasing flow of information in small-scale companies to large-sized companies. This means that advances in mobile technology are critical for mobile supply chains. In this sense, this paper examines mobile sector in Turkey and analyze how the value of information technology in mobile supply chains presents a growing opportunity in Turkish markets.
\end{abstract}

Keywords: Mobile Supply Chain Management, Mobile Commerce, Mobile Sector in Turkey.

\section{Introduction}

In today's global, competitive and dynamic business environment, the competitions among enterprises have transformed from company versus company to supply chain management versus supply chain management [1]. These days implementing techniques that reduce project time and cost, and improve productivity and performance is very important. The need for new ways to face these challenges has long been recognized. Recent years have also seen a movement towards using methods that influence and effect on the internet platform [2]. In today's economic globalization era, customers' expectations are very different to those of a few years ago. They demand the exact products they want, when they want them, at the right price. Each of the five major supply chain steps (Plan, Source, Make, Store and Deliver) need to be integrated and harmonized into a single application in order to derive maximum value from the supply chain and meet customer expectations [3]. Nowadays, more and more enterprises have paid or are paying attention to replace 
traditional linear supply chains with mobile and adaptive supply chain management, helping firms to reduce management cost and gain supply chain responsiveness or other competitive advantage [4]. With the development of communication technologies and mobile networks, the supply chain management in the mobile environment has become more and more prevalent and necessary [5]. The Internet has many impacts on the supply chain. One of the most covered topics in the literature is the impact of $e$-business, which refers to the ability of a firm to electronically connect, in multiple ways, many organizations, both internally and externally, for many different purposes [6]. Another impact refers to information sharing, how the Internet can be used as a medium to access and transmit information among supply chain partners [7].

\section{Mobile Commerce}

Today, the e-commerce is increasing prevalence, internet technology is more secure and well-developed, the computer hardware and software equipment are more advanced, advanced mobile communication technology is widely used in the field of logistics, all of these directly spawn the mobile supply chain management [8].

In the literature, all mobile commerce definitions are very similar. In principle, any transaction with a monetary value conducted via mobile communication networks can be considered mobile commerce [9]. Dependent on this definition, [10] define mobile commerce as a new type of e-commerce transaction conducted through mobile devices using wireless telecommunication networks and other wired e-commerce technologies; [11] defines mobile commerce as the application of wireless communications networks and devices to the execution of transactions with monetary value; [12] define mobile commerce as any form of mobile communication between a business and its customer; [13] define mobile commerce for electronic commerce transactions carried out via mobile phones [14].

Mobile commerce is generally defined as conducting information inquires and/or any transaction with monetary value by using mobile devices wireless communications [15;16] Wireless and mobile networking have presented an entire new way for companies to further extend their supply chain-mobile commerce. Mobile commerce has extended the functions of e-commerce and thus the e-supply chain system to previously unimagined dimensions [17]. With mobile applications, the supply chain system will be accessible anywhere anytime by various devices, such as PCs, TVs, PDAs, and cellular phones. A number of m-commerce applications have been developed and are already use, covering a wide range of business functions from advertising, banking, ticketing, booking, games, to payment on the Internet, and payments of goods and services in shops, restaurants and corner stores [18;16]. With the advancement of this technology, mobile commerce is undergoing a rapid growth and exerting significant impacts on the business. Developments in mobile technology and use of mobile phones by consumers have made the mobile commerce market more consumer-oriented, more global in scope and more device-dependent $[19 ; 14]$. The forces underpinning the emergence of mobile commerce can be summarized as (1) proliferation of mobile devices, (2) convergence of mobile telecommunication networks and Internet, (3) transition 3G, and (4) the emergence of broad set of highly personalized location applications and services [20;14] 


\section{The Basis of the Mobile Supply Chain Management (mSCM)}

The essence of the supply chain is the network of communication through each link within the "chain" [21]. In order to make the most informed, intelligent decisions for their business, managers needed the ability to obtain information in real time from each stage in the process [21]. The objective of a favorable supply chain management should ensure to deliver the right product, at the appropriate time, at the competitive cost, and with customer satisfaction for keeping the competitive advantages [22]. The supply chain is involved in the information flow, materials flow and funds flow from suppliers to customers [3]. The mSCM causes timesaving and highly accurate means of capturing data on movements of goods and other events [2]. Mobile SCM is based on the traditional supply chain management platform to integrate existing mobile communication technology, computer hardware and software technology and Internet technology, which implements the Real-time management of a specific logistics part in order to achieve: internally reducing business costs, externally improving customer response time, enhancing the competitiveness of the whole supply chain [8].

Mobile SCM is to use the most advanced mobile communication technology and facilities to promote the rapid flow of capital, information, business logistics, enhancing operational efficiency and effectiveness of the supply chain participants [8]. Managing and sailing the Web content to mobile users, based on their preferences and locations and controlling the products during producing, distributing, logistics and delivering are becoming now a leading point in a mobile electronic commerce (m-commerce) and mobile supply chain management [2]. Mobile SCM also refers to the use of mobile applications and devices to aid the conduct of supply chain activities, and ultimately help firms to gain cost reductions, supply chain responsiveness and competitive advantage [23].

\subsection{The Features of Mobile Supply Chain}

The mobile supply chain management is not to replace the original supply chain management platform. Mobile supply chain management is a part of supply chain management, the relationship between them is the overall and local [8]. Mobile supply chain system supports the interface of a mobile client device with a networked computer system [24]. Simply speaking, mobile supply chain management is only through the mobile communication technology and equipment to achieve some of the traditional supply chain management functions, to a certain extent, mSCM extends and expands these features [25]. Mobile SCM is highly targeted, especially for information processing. The $\mathrm{mSCM}$ solution takes supply chain visibility to new levels. It facilitates a convenient, time-saving, and highly accurate means of capturing data on movements of goods and other events. These capabilities simplify checking and monitoring tasks and provide up-to-date information on process status, which can be shown in mobile production management, mobile inventory management, mobile shipment planning, mobile sales management and Event Management [24].

Mobile SCM expands the traditional supply chain functions; information sharing and real-time delivery can improve the interactivity and integration capabilities of the members, and then can improve the whole supply chain competitive advantage [8]. 
From the perspective of supply management, mSCM has a high degree of flexibility, intelligence and accuracy [8].

\subsection{The Applications of Mobile Supply Chain Management}

Mobile supply chain applications introduce new challenges particularly for implementation. Mobile technology extends SCM capabilities through new virtual and remote ways of conducting supply chain activities [23]. With the characteristics of mobile commerce and its enabling technologies described above, mobile commerce has the potential to make information flows more efficient, coordinate the operations within the extended enterprise, and thus improve SCM [26]. Discussed below are methods detailing how mobile commerce can prepare organizations to meet the challenges imposed upon SCM.

Mobile email and Internet for corporate users: Mobile email is the key application for wireless data usage. It serves as the primary communication link for corporate users to stay in touch with their organizations while on the move [26].

Mobile customer care: Mobile commerce can provide customers automated, unassisted operations directly from mobile terminals [26].

Mobile enterprise implementations: Mobile commerce can be used to manage logistics and work flow and streamline inventory and distribution control. For example, Bluetooth devices are ideal for inventory control [26].

Mobile Logistics Management: MSCM enables more efficient circulation of the cargos or assets in supply chain [3].

Mobile Supply and Marketing Management: Through mobile supply and marketing management, second tier suppliers or second-tier distributors can make real-time information interaction with core enterprises, strengthen the channel controlling capability of core enterprises, shorten the distances among numerous second-tier distributors which locate in wide area and core enterprises or first-tier suppliers and distributors, so that they are more closely connected [3].

Mobile Manufacturing Management: Basically, mSCM realizes the real-time interaction between managers and workers in a factory [3].

Mobile Inventory Management: By utilizing mobile equipments or wireless devices, the inventory and management capability for raw materials of enterprises is greatly increased [3].

\section{The Evaluation Mobile Sector of Turkey for Potential MSCM Applications}

There have been significant changes in telecommunications market in last few decades. During this time period, innovative new technologies changed people's lifestyles and the way people communicate. Demand and interest of consumers to new telecommunication services are growing up rapidly which in turn makes the competition among operators more intense.

There are several factors that caused this significant growth in mobile market. First, the privatization and regulation of telecommunications market in most countries allowed new players to enter the market and provide innovative mobile services with 
lower rates. Second, mobile phone manufactures have been able to offer more capable phones at more economical prices by utilizing economics of scale. As a consequence, demand for mobile phone increased which resulted even smarter and more user friendly mobile phones.

Turkey is the country which is connecting Europe and Asia. Geopolitical position is one of the most important factors in increasing mobile sector. It promotes ICT sector especially supply side. Turkish companies can reach the source which is they need easily. On the demand side, especially young people are highly interested in technological improvements. The median age of Turkey, which has a young population structure, is 28.8 [27]. During the past decade, mobile phone has surged to the forefront of the Turkish telecommunications industry [14]. Mobile communication market is rapidly growing. By the end of 2010 , $90 \%$ of population had adopted mobile phones. The number of mobile phone subscribers in Turkey had exceeded 73 million (73 722988 ) by 2010 [28].

Mobile internet subscribers are rapidly growing after $3 \mathrm{G}$ service introduced in 2009. According to these improvements, mobile internet demand is increasing in Turkish mobile sector. Mobile internet prices also affected the usage of the technology. The gap between fixed line and mobile internet prices are closing. As a result the annual growth rate for the last quarter between 2010-2011 reached \% 345, 8 (Table 1). In the meantime, broadband subscribers' rate is increasing according to connecting availability [29].

Table 1. Internet Subscribers in Turkey [29]

\begin{tabular}{|l|l|l|l|l|l|}
\hline & $2010-4$ & $2011-3$ & $2011-4$ & $\begin{array}{l}\text { Quarter growth rate } \\
(2011-3-2011-4)\end{array}$ & $\begin{array}{l}\text { Annual growth rate } \\
(2010-4-2011-4)\end{array}$ \\
\hline xDSL & 6.640 .911 & 6.792 .013 & 6.776 .036 & $-0,2 \%$ & $2,0 \%$ \\
\hline $\begin{array}{l}\text { Mobile } \\
\text { Internet }\end{array}$ & 1.448 .020 & 5.655 .444 & 6.454 .801 & $14,1 \%$ & $345,8 \%$ \\
\hline $\begin{array}{l}\text { Cable } \\
\text { Internet }\end{array}$ & 273.908 & 407.502 & 460.451 & $13,0 \%$ & $68,1 \%$ \\
\hline Fiber & 154.059 & 220.777 & 267.144 & $21,0 \%$ & $73,4 \%$ \\
\hline Other & 155.478 & 129.858 & 159.383 & $22,7 \%$ & $2,5 \%$ \\
\hline Total & $\mathbf{8 . 6 7 2 . 3 7 6}$ & $\mathbf{1 3 . 2 0 5 . 5 9 4}$ & $\mathbf{1 4 . 1 1 7 . 8 1 5}$ & $\mathbf{6 , 9 \%}$ & $\mathbf{6 2 , 8 \%}$ \\
\hline
\end{tabular}

Table 2. 3G Subscribers Data in Turkey 2010-2011 [29]

\begin{tabular}{|l|c|c|r|}
\hline & $\mathbf{2 0 1 0 - 4}$ & $\mathbf{2 0 1 1 - 3}$ & \multicolumn{1}{|c|}{$\mathbf{2 0 1 1 - 4}$} \\
\hline 3G subscribers & 19.407 .264 & 28.608 .069 & 31.375 .507 \\
\hline Mobile internet subscribers & 1.448 .020 & 5.655 .444 & 6.454 .954 \\
\hline Mobile internet usage, Gbytes & 4.387 .315 & 8.766 .845 & 10.708 .533 \\
\hline
\end{tabular}

While the ratios of computer usage and Internet access in enterprises were $87.8 \%$ and $80.4 \%$, respectively, in January 2005, these levels increased to $92.3 \%$ and $90.9 \%$ in January 2010 [27] .Even though these two ratios increased by years, a downward trend is seen in web page ownership. The web page ownership rate of enterprises with Internet access dropped from $63.1 \%$ in January 2007 to 57.8\% in January 2010 [27]. To give an example, while computer usage, Internet access, and web page ownership 
rates were around $91.3 \%, 89.7 \%$, and $53.5 \%$, respectively in enterprises with $10-49$ employees in 2010 , these rates were around $98.5 \%, 98.4 \%$, and $88.8 \%$ for enterprises with 250+ employees. [27].

The type of connection most frequently used by enterprises for Internet access in January 2010 was DSL (ADSL, etc.) represented by $87.3 \%$. With the spreading of the $3 \mathrm{G}$ technology as of 2010, a serious increase was observed in the rate $12.9 \%$ of enterprises using mobile broadband connection with the help of portable computers [27].

When we compare connection types with europe avarage, mostly xDSL connection type is prefered with $93,5 \%$ in Turkey. However, it is only $79 \%$ in Europe avarage [28]. The year 2009 is a milestone for mobile internet users. Introducing $3 \mathrm{G}$ techology caused fast mobile internet experiences. At the begining, $3 \mathrm{G}$ subscribers were $\% 7,1$ of total mobile internet subscribers. At the end of the 2010, this rate increased to $19,4 \%$.

When the mobile internet penetration rates are compared with those of the EU, Europe average is \%126 however Turkey has only \% 89 penetration rates after Norway and France. In addition to this ratio, we can examine mobile broadband connection penetration according to population. Finland is in the first place with \%21,5. European average is 6,1\% between Poland and Holland. Following Ireland, Portugal and Sweden, Turkey is in the seventh place with 8,8\% [29].

We aimed to increase the ICT usage throughout our country and to close the gap with developed countries. However, even though a progress was made during the 2007 - 2009 period, the difference in terms of ICT usage still continues between the EU and our country (The values for the EU were obtained from EUROSTAT (as of June 2010) and those for Turkey were obtained from TURKSTAT. The value for Turkey concerning 2006 is an estimate of the SPO [27].

Another matter that needs to be evaluated is the Internet access and broadband Internet ownership in households. Even though a significant increase was achieved during the 2007-2009 period, as in the Internet usage, there is a major difference between our country and the EU in terms of the ratios of Internet access and broadband Internet ownership in households [30: 31]. When the Internet access ownership rates of the enterprises of Turkey are compared with those of the EU, a significant tendency of convergence is observed by years until 2008; however, this convergence is seen to have receded in 2009. While the ratio of Internet access by the enterprises in our country increased from $80.4 \%$ in 2005 to $89.2 \%$ in 2008 by displaying a major progress in three years, this rate receded back to $88.8 \%$ in 2009 . In the EU this ratio reached the levels of $93-95 \%$ in 2008 and $94-96 \%$ in 2009 from $91-92 \%$ in 2005 [30: 31]. In addition to this, the enterprises in Turkey showed a higher convergence to the EU in terms of broadband Internet access in 2007 and 2008 and reached a ratio higher than the average values of the EU 25 and EU 27. However, this ratio showed a slight drop in 2009 and took place between the average values for the EU 25 and EU 27.

In addition to this, the enterprises in Turkey showed a higher convergence to the EU in terms of broadband Internet access in 2007 and 2008 and reached a ratio higher than the average values of the EU 25 and EU 27. However, this ratio showed a slight drop in 2009 and took place between the average values for the EU 25 and EU 27 (The values for the EU were obtained from EUROSTAT (as of June 2010) and those for Turkey was obtained from TURKSTAT). 


\section{Conclusions}

Supply chain transformation is proceeding at the same speed as technological developments. The two most important factors driving this transformation in supply chains are: an increasingly competitive environment and customer awareness. In order to compete in the market place, mobile supply chains remedy their products and services in order to meet the needs of the increasing flow of information in smallscale companies to large-sized companies. This means that advances in mobile technology are critical for mobile supply chains to ensure swift and accurate data transmission for their customers

In the meantime, analysis of the potential of mobile supply chains with an information technology perspective is an important issue in Turkey. The concept of mobile characteristics meets the needs of Turkish firms. Along with globalization, Turkish firms should continuously upgrade their supply chains with the latest in information technology.

This situation represents a growing opportunity for mobile supply chains in Turkey. However, one of the biggest obstacles facing the mobile supply chain transition process appears to be the lack of information technology within the infrastructure of Turkish firms. In addition, corporate culture along with revision of business processes also present formidable problems that threaten to delay this transition. Ubiquitous business efficiency and customization are some of the major advantages in mobile supply chains.

\section{References}

1. Barbuceanu, M., Fox, M.: Coordinating multiple agents in the supply chain. In: Proceedings of the Fifth Workshops on Enabling Technology for Collaborative, pp. 134-141 (1996)

2. Zarei, S.: RFID In Mobile Supply Chain Management Usage. International Journal of Computer Science and Technology 1(1), 11-20 (2010)

3. Zha, M., Lui, X., Zhang, Z.: Research on Mobile Supply Chain Management Based Ubiquitous Network, pp. 1-4 (2008)

4. Öztemel, E., Kurt Tekez, E.: Interactions of agents in performance based supply chain management. Journal of Intelligent Manufacturing 20, 159-167 (2009)

5. Zhao, W., Wu, H., Dai, W., Xuan, L.: Integration Middleware for Mobile Supply Chain Management. In: Proceedings of the Second Symposium International Computer Science and Computational Technology, ISCSCT 2009, pp. 521-524 (December 2009)

6. Fahey, L., Srivastava, R., Sharon, J., Smith, D.: Linking e-business and operating processes: The role of knowledge management. IBM Systems Journal 40(4), 889-907 (2001)

7. Giménez, C., Lourenço, H.R.: Supply Chain Management: review implications and directions for future research. Document de Treball / Working Paper, 17 (October 2004)

8. Li, L., Guo, W., Wang, Y.: Mobile Supply Chain Management:Theory and Method. In: 2010 International Conference on E-Product E-Service and E-Entertainment (ICEEE), pp. 1-8 (November 2010)

9. E-Business Report, Mobile E-Business- Mobile Commerce, European Commission Enterprise Directorate General, No. 3 (2000)

10. Siau, K., Lim, E.P., Shen, Z.: Mobile commerce: promises, challenges, and research agenda. Journal of Database Management 12(3), 4-13 (2001) 
11. Clarke, I.: Emerging value propositions for mobile commerce. Journal of Business Strategies 18(2), 133-148 (2001)

12. Frolick, M.N., Chen, L.D.: Assessing mobile commerce opportunities. Information Systems Management 21(2), 53-61 (2004)

13. Dholakia, R.R., Dholakia, N.: Mobility and markets: emerging outlines of mobile commerce. Journal of Business Research 57(12), 1391-1396 (2004)

14. Barutçu, S.: Customers' Attitudes Towards Mobile Commerce and Mobile Marketing in Consumer Markets. Review of Social, Economic \& Business Studies 9/10, 29-56 (2010)

15. Barnes, S.J.: The mobile commerce value chain: analysis and future developments. International Journal of Information Management 22(2), 91-108 (2002)

16. Wei, W., Shen, J., Ji, S.: Introducing Mobile Channel into Electronic Supply Chain. In: The 3rd International Conference on Grid and Pervasive Computing - Workshops, pp. 121-127 (2008)

17. Siau, K., Shen, Z.: Mobile Commerce Applications in Supply Chain Management. Journal of Internet Commerce 1(3), 3-16 (2002)

18. Kreyer, N., Pousttchi, K., Turowski, K.: Mobile payment procedures. e-Service Journal 2(3), 7-22 (2003)

19. DSTI/CP (Final Directorate for Science, Technology and Industry Committee on Consumer Policy), Mobile Commerce, OECD/OCDE (2006)

20. Sadeh, N.: Mobile commerce: Technologies, Services, and Business Models. Wiley Computer Publishing, New York (2002)

21. Airclick. the mobile supply chain of the future (July 20, 2011), http: //www.airclic.com/download/ac.whitepaper.mobility_100929. pdf

22. Yonghui, F., Rajesh, P.: Multi-agent enabled modeling and simulation towards collaborative inventory management supply chains. In: Proceedings of the 2000 Winter Simulation Conference, pp. 1763-1771 (2000)

23. Eng, T.-Y.: Mobile supply chain management: Challenges for implementation. Technovation (26), 682-686 (2006)

24. Qi, Y., Zhao, X., Zhang, Q.: Key Technology and System Design in Mobile Supply Chain Management. In: International Symposium on Electronic Commerce and Security, pp. 258-263 (2008)

25. Wang, M.: Supply chain management development under E-commerce environment mobile supply chain management. Public Automation Magazine 9 (2006)

26. Siau, K., Shen, Z.: Mobile Commerce Applications in Supply Chain Management. Journal of Internet Commerce 1(3), 3-16 (2002)

27. Republic of Turkey Prime Ministry, Undersecretariat for State Planning. Information Society Statistics. Ankara, Turkey: Republic of Turkey Prime Ministry, pp. 1-202 (2011)

28. Turkish Statistical Institute (2011), Turkey in Statistics 2010, TÜİK (June 08, 2012), http: / / www.tuik.gov.tr/IcerikGetir.do?istab_id=5

29. Organization of Information Technologies and Communication (May 2011). The Sector of Turkey Electronic Communication, Three Months Market Data Report (April 29, 2012), http://www.btk.gov.tr/kutuphane_ve_veribankasi/pazar_verileri/ ucaylik11_4.pdf

30. EUROSTAT (2010),

http: / /epp.eurostat.ec.europa.eu/cache/ITY_OFFPUB/

KS-QA-10-049/EN/KS-QA-10-049-EN.PDF,

http: / / epp.eurostat.ec.europa.eu/cache/ITY_OFFPUB/ KS-QA-10-049/EN/KS-QA-10-049-EN. PDF (July 24, 2011)

31. TURKSTAT (2010), http://www.tuik.gov.tr/VeriBilgi.do?tb_id=60\&u st_id=2(July 24, 2011) 